\title{
Valve-sparing repair with intraoperative balloon dilation in tetralogy of Fallot: Midterm results and therapeutic implications
}

\author{
Sophie C. Hofferberth, MBBS, ${ }^{a}$ Meena Nathan, MD, ${ }^{a}$ Gerald R. Marx, MD, ${ }^{a}$ Minmin Lu, MS, ${ }^{b}$ \\ Lynn A. Sleeper, ScD, ${ }^{\text {b,c }}$ Audrey C. Marshall, MD, ${ }^{b}$ Christopher W. Baird, MD, ${ }^{a}$ John E. Mayer, MD, \\ Pedro J. del Nido, MD, ${ }^{a}$ and Sitaram M. Emani, MD ${ }^{\mathrm{a}}$
}

\section{ABSTRACT}

Objectives: The significant morbidity of long-term pulmonary regurgitation (PR) has driven the development of pulmonary valve (PV) sparing repair strategies in patients with tetralogy of Fallot (ToF). We assessed mid-term PV function in patients who underwent primary ToF repair with valve-sparing intraoperative balloon dilation (IBD) technique.

Methods: We evaluated 162 consecutive patients with ToF and pulmonary stenosis (ToF-PS) who underwent valve-sparing repair with IBD under 1 year of age.

Results: Median age at surgery was 98 days (interquartile range [IQR], 72-126) and median follow-up was 2.5 years (IQR, 0.6-4.9). Median preoperative PV annulus $z$ score was -2.2 (IQR, -2.5 to -1.8 ). Twenty-five patients $(15.4 \%$ ) required reintervention for residual valvular stenosis. Multivariable analysis demonstrated preoperative annulus $z$ score less than $-2.45(P=.036)$ and younger age at surgery $(P=.001)$ were independent risk factors for early reintervention for stenosis. Freedom from at least moderate PR was $77 \%, 61 \%$, and $43 \%$ at 1,3 , and 5 years postrepair. Right ventricular dimensions were not significantly different compared with a matched cohort of patients undergoing transannular patch repair at midterm follow-up.

Conclusions: Patients with ToF-PS who undergo valve-sparing repair with IBD develop progressive PR. Compared with transannular patch repair, the extent of RV dilation at midterm follow-up is not significantly different. Patients younger than 3 months of age and those with an annulus $z$ score less than -2.45 experience higher rates of early reintervention for PV stenosis. In these patient subgroups, alternative strategies should be considered. This study suggests valve-sparing repair with IBD does not preserve long-term PV function in patients with ToFPS. (J Thorac Cardiovasc Surg 2018;155:1163-73)

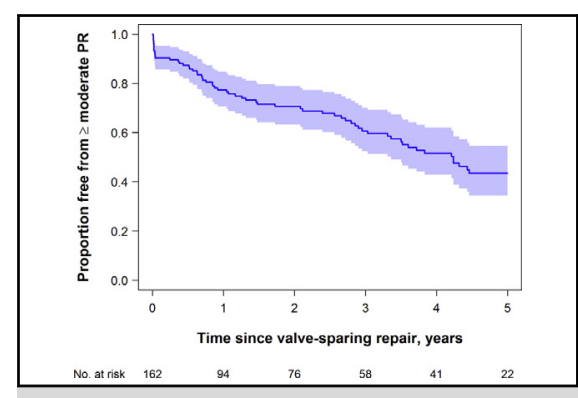

Freedom from at least moderate pulmonary regurgitation (PR) after valve-sparing tetralogy of Fallot repair.

\section{Central Message}

Patients who undergo complete primary repair of tetralogy of Fallot with valve-sparing intraoperative balloon dilation technique develop progressive pulmonary valve insufficiency.

\section{Perspective}

Valve-sparing repair with intraoperative balloon dilation (IBD) has been increasingly adopted in the management of patients with tetralogy of Fallot (ToF) This technique is associated with development of progressive pulmonary insufficiency and right ventricula dilation. Our study suggests that valve-sparing repair with IBD is not a suitable long-term solution to preserve pulmonary valve function in patients with ToF.

See Editorial Commentary page 1174.

See Editorial page 1161
From the Departments of ${ }^{\mathrm{a} C}$ ardiac Surgery and ${ }^{\mathrm{b}}$ Cardiology, Boston Children's Hospital, and ${ }^{\mathrm{c}}$ Pediatrics, Harvard Medical School, Boston, Mass.

Supported by Departmental funds.

Read at the 97th Annual Meeting of The American Association for Thoracic Surgery, Boston, Massachusetts, April 29-May 3, 2017.

Received for publication April 7, 2017; revisions received July 23, 2017; accepted for publication Aug 28, 2017; available ahead of print Dec 6, 2017.

Address for reprints: Sitaram M. Emani, MD, Department of Cardiac Surgery, Boston Children's Hospital, Harvard Medical School, 300 Longwood Ave, Boston, MA 02115 (E-mail: Sitaram.emani@cardio.chboston.org).

$0022-5223 / \$ 36.00$

Copyright (c) 2017 by The American Association for Thoracic Surgery

https://doi.org/10.1016/j.jtcvs.2017.08.147
Tetralogy of Fallot (ToF) is the most common cyanotic congenital heart defect, occurring in approximately 1 in every 3600 live births and accounting for up to $10 \%$ of

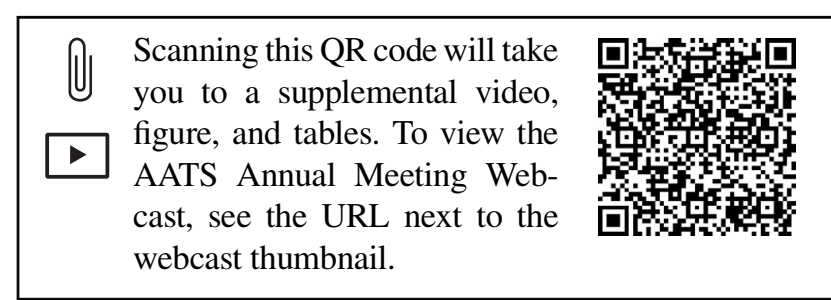




$$
\begin{array}{ll}
\text { Abbreviations and Acronyms } \\
\text { EDA } \quad \text { end diastolic area } \\
\text { IBD } \quad \text { intraoperative balloon dilation } \\
\text { PR } \quad \text { = pulmonary regurgitation } \\
\text { PS } \quad=\text { pulmonary stenosis } \\
\text { PV } \quad \text { pulmonary valve } \\
\text { RV } & =\text { right ventricular } \\
\text { RVOT } & =\text { right ventricular outflow tract } \\
\text { TAP } & =\text { transannular patch repair } \\
\text { ToF } & =\text { tetralogy of Fallot } \\
\text { TOF-PS } & =\text { tetralogy of Fallot-pulmonary stenosis } \\
\text { TPS } & =\text { technical performance score } \\
\text { TTE } & =\text { transthoracic echocardiogram }
\end{array}
$$

all congenital cardiac anomalies. ${ }^{1,2}$ Contemporary management has evolved to elective primary repair in early infancy. ${ }^{3,4}$ Surgical augmentation of the right ventricular outflow tract (RVOT) may be accomplished by transannular patch (TAP) reconstruction or valve-sparing approaches. ${ }^{5-10}$ TAP repair remains the most widely used strategy. ${ }^{11}$ However, a critical shortcoming is the loss of valve structural integrity and induction of chronic severe pulmonary regurgitation (PR). Progressive right ventricular (RV) dilation, exercise intolerance, biventricular dysfunction, ventricular arrhythmias, and sudden cardiac death are well-recognized late sequelae of chronic PR in patients with repaired ToF. ${ }^{12-14}$ This has led to the practice of pulmonary valve (PV) replacement in patients with repaired ToF with pronounced RV dilation. ${ }^{15}$

To avoid the late sequelae of PR and reoperation, recent surgical efforts have focused on PV preservation at the time of primary ToF repair. ${ }^{10,16-19}$ In patients with ToF and PV annulus hypoplasia, preservation of native valve architecture must be balanced against adequate relief of outflow obstruction. Leveraging prior experience with transcatheter balloon valvuloplasty, ${ }^{20,21}$ our center adopted the approach of valve-sparing repair with intraoperative balloon dilation (IBD) for ToF-PS in $2007 .{ }^{8}$ This study evaluates mid-term PV function and RV remodeling in patients who underwent complete primary repair of ToF and pulmonary stenosis (TOF-PS) with valve-sparing IBD technique over an 8 year period.

\section{METHODS}

\section{Surgical Technique: Valve-Sparing Repair With IBD}

On cardiopulmonary bypass, and under cardioplegic arrest and moderate hypothermia, the infundibulum is incised vertically to just below the level of the PV annulus, and continued in a $T$-shaped fashion, extending parallel to the annulus, remaining within RV muscle. Parietal and septal muscle bundles are resected and the ventricular septal defect closed. A longitudinal main pulmonary artery arteriotomy is then performed and the PV is inspected. After sharp commissurotomy, a rigid Hegar dilator is used to accurately size the valve annulus to inform initial balloon diameter, usually sized to $120 \%$ to $140 \%$ of the measured annulus. Antegrade balloon deployment and hand inflation allows radial dilation of the annulus with leaflet preservation. The main pulmonary artery and infundibulum are subsequently patch augmented with autologous or bovine pericardium (Video 1).

\section{Study Cohort and Data Collection}

Institutional review board approval with waiver of consent was obtained for this retrospective, single-center analysis of all patients younger than age 1 year who underwent primary repair of ToF-PS with valve-sparing IBD technique between April 2007 and December 2015. Patients with ToF and pulmonary atresia, absent PV, or major aortopulmonary collaterals, and/or coexisting complex intracardiac defects, were excluded. Over the study period, 45 patients (PV annulus $z$ score greater than -1.8) underwent valve-sparing repair via commissurotomy, whereas 40 patients (PV annulus $z$ score less than -3 ) underwent TAP repair.

Data collected included patient demographic characteristics, prior interventions, operative details, postoperative complications, reinterventions, and mortality. Adequacy of valve-sparing repair was evaluated using a PV-specific technical performance score (TPS), ${ }^{22}$ (Table 1). We defined RVOT TPS as class 1 (RVOT peak gradient $<20 \mathrm{~mm} \mathrm{Hg}$, none/trivial PR), class II (RVOT peak gradient $20-40 \mathrm{~mm} \mathrm{Hg}$ or mild PR), or class III (RVOT peak gradient $>40 \mathrm{~mm} \mathrm{Hg}$ or moderate or greater PR).

\section{Echocardiographic Analysis of PV Annulus and RV}

A single reviewer independently measured all available preoperative, discharge and follow up 2-dimensional transthoracic echocardiogram (TTE) studies. A second independent and blinded reviewer measured a random sample. Serial measurements of PV annulus diameter and RV dimensions (end diastolic planimetered area [EDA]), each indexed to body surface area, were obtained using standard views recommended by published guidelines. ${ }^{23-25}$ Echocardiogram reports were reviewed for diameter and $z$ scores of the main and proximal branch pulmonary arteries, degree of $\mathrm{PR}$, residual RVOT obstruction, RV pressure, and qualitative biventricular function. Grading of PR was evaluated qualitatively as many patients were followed at outside institutions, with

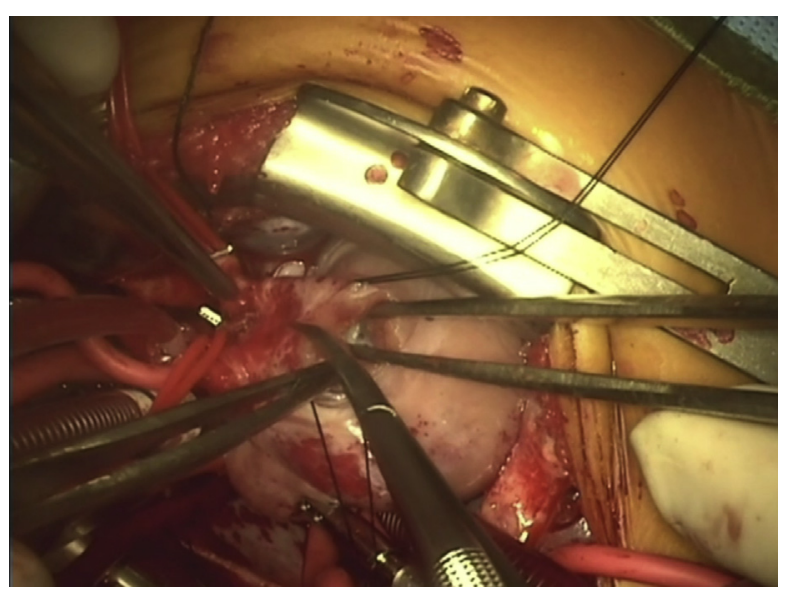

VIDEO 1. Valve-sparing repair with intraoperative balloon dilation technique, demonstrating infundibulotomy incision extended superiorly in $T$-shaped fashion to just below level of annulus, pulmonary valve commissurotomy, annulus balloon dilation, and patch augmentation of main pulmonary artery and infundibulum. Video available at: http:// www.jtcvsonline.org/article/S0022-5223(17)32504-7/fulltext. 
TABLE 1. Baseline patient characteristics and procedure details

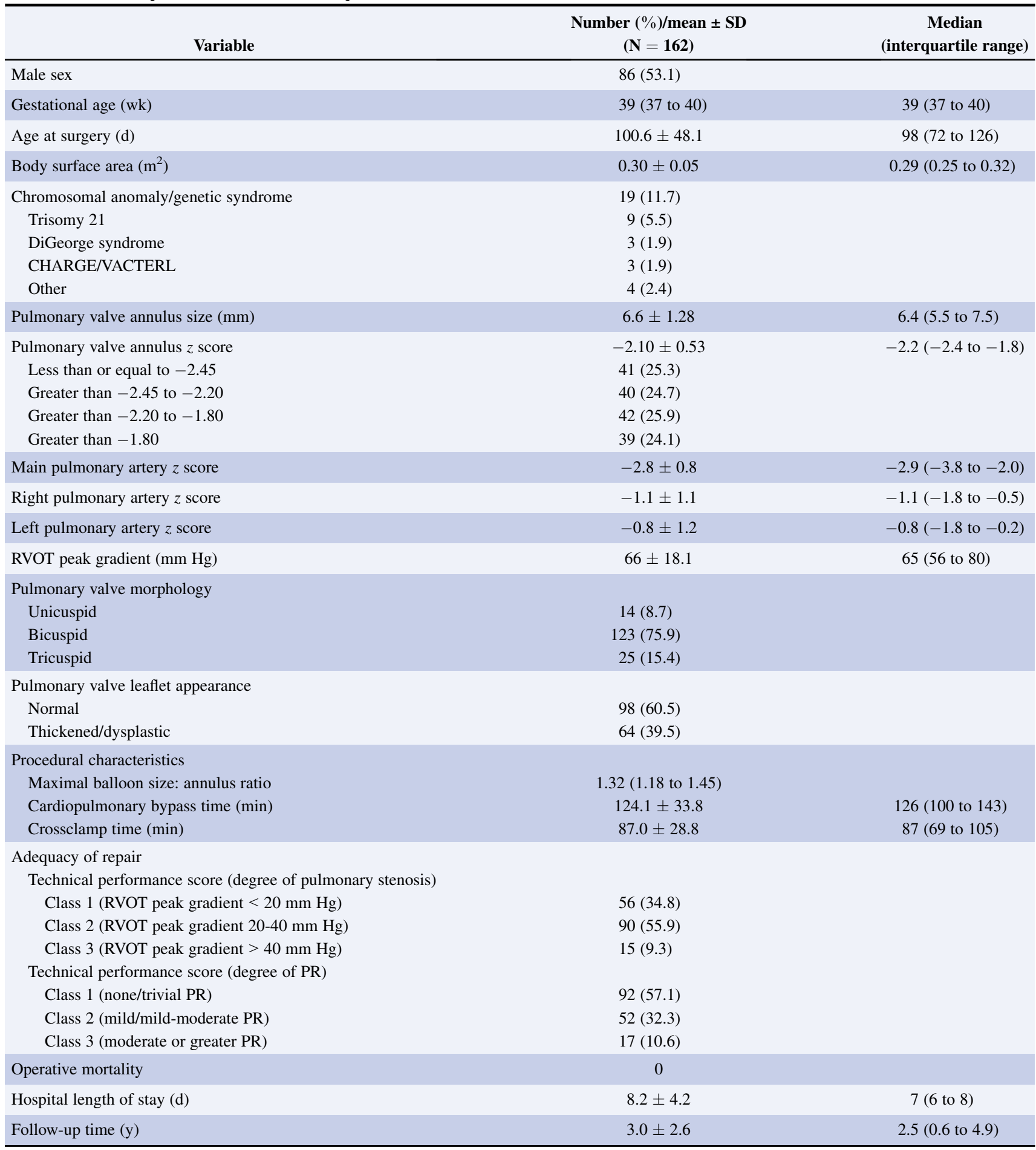

Data are presented as $\mathrm{n}(\%)$, mean \pm standard deviation, or median (interquartile range). $S D$, Standard deviation; RVOT, right ventricular outflow tract; $P R$, pulmonary regurgitation.

limited ability to review external echocardiograms. Patients with moderate or severe PR documented on 2 consecutive postoperative TTE studies/ reports were classified as having significant PR. The date of the first TTE in the qualifying pair was defined as the onset of significant PR.

\section{Matched Cohort Analysis: Valve-sparing Versus TAP Repair}

Given the lack of standardized echocardiographic measures of RV size in pediatric patients, we compared longitudinal RV remodeling in the 
TABLE 2. Multivariable Cox regression model of factors associated with pulmonary valve $(\mathrm{PV})$ reintervention $\left(\mathrm{N}=162 ; \mathrm{N}\right.$ events $\left.=25 ; R^{2}=0.21\right)$

\begin{tabular}{|c|c|c|c|}
\hline Variable & Hazard ratio & 95 $\%$ Confidence interval & $P$ value \\
\hline Pulmonary valve annulus $z$ score & & & .036 \\
\hline Less than or equal to $-2.45^{*}$ & 4.47 & $1.24-16.09$ & \\
\hline Greater than -2.45 to less than or equal to -2.0 & 1.97 & $0.52-7.47$ & \\
\hline Greater than -2.0 & Reference & & \\
\hline Age at surgery (wk) & 0.89 & $0.83-0.95$ & .001 \\
\hline TPS (residual pulmonary stenosis) & & & .002 \\
\hline Class 1 & Reference & & \\
\hline Class 2 & 2.69 & $0.76-9.49$ & \\
\hline Class $3 \dagger$ & 10.59 & $2.64-42.4$ & \\
\hline
\end{tabular}

TPS, Technical performance score. Bold indicates: *PV $z$ score $\leq-2.45$ vs PV $z$ score $>-2.45$ to $\leq-2.0$, hazard ratio $=2.27 ; 95 \%$ CI, $0.93-5.55$. $\dagger$ Class 1 TPS vs class 2 TPS hazard ratio $=3.93 ; 95 \% \mathrm{CI}, 1.54$ to 10.04

ToF/valve-sparing cohort to a matched control population. The comparison group consisted of ToF-PS patients (same exclusion criteria as detailed previously), matched by age at surgery and preoperative PV annulus $z$ score, who underwent primary ToF-PS repair via TAP in the decade before introduction of valve-sparing repair with IBD (1997-2006). Longitudinal changes in RV dimensions were compared between the 2 matched cohorts. Among TAP patients who underwent PV replacement, RV EDA measurements were performed on all available echocardiograms before reintervention.

\section{Study Outcomes}

Primary study end points were early (within 2 years) PV reintervention for residual valvar stenosis, midterm PV competency, longitudinal changes in RV dimensions, and late PV replacement for RV dilation secondary to PR. A secondary end point was longitudinal PV annulus growth.

\section{Statistical Analysis}

Data were summarized using mean \pm standard deviation or median (interquartile range $[\mathrm{IQR}]$ ), depending on continuous variable distribution. Categorical variables were summarized using frequency and percentage. Kaplan-Meier method estimated freedom from PV reintervention and development of significant PR, distributions of time to event were compared using log-rank test. Risk factors for PV reintervention and development of significant PR were examined using Cox proportional hazards regression model. Continuous predictors were also categorized by tertile to assess association with outcome. Linear mixed effect model with an unstructured variance covariance structure was used to assess indexed RV EDA over time. A $P$ value of .05 was considered statistically significant. Analyses were performed using Statistical Analysis System version 9.3 (SAS Institute Inc, Cary, NC) and S-Plus 8.0 (Insightful Corp, Seattle, Wash).

\section{RESULTS}

Between April 2007 and December 2015, 162 consecutive patients underwent complete primary repair of ToFPS with valve-sparing IBD technique at younger than age 1 year. Median age and weight at surgery was 98 days (IQR, 72-126 days) and $5.4 \mathrm{~kg}$ (IQR, 4.6-6.1 kg), respectively. The cohort included 11 neonates $(7 \%)$. Baseline patient characteristics, operative and postoperative data are outlined in Table 1. Nine patients $(6 \%)$ underwent catheter-based pulmonary valvotomy before primary repair and 2 patients $(1 \%)$ had concomitant branch pulmonary artery dilation. Median preoperative PV annulus $z$ score was -2.2 (IQR, -2.4 to -1.8 ).

Details of the operative approach are outlined in Table 1. A median of 2 (IQR, 1-2) balloon dilations were performed per patient. Median maximal balloon size was $9 \mathrm{~mm}$ (IQR, 8$9 \mathrm{~mm}$ ). Final nominal balloon size to preoperative annular diameter ratio was 1.32 (IQR, 1.18-1.45). Maximal balloon inflation pressure was a median of 16 atmospheres (IQR, $15-16$ atmospheres). Thirty-two patients (20\%) had a leaflet tear or partial leaflet avulsion detected intraoperatively. Eighteen of 32 patients underwent immediate leaflet repair, including single suture repair in 11 patients, pericardial patch valvuloplasty in 6 patients, and intraoperative conversion to TAP in 1 patient. At the conclusion of cardiopulmonary bypass, median RV pressure was $38 \mathrm{~mm} \mathrm{Hg}$ (IQR, 30$42 \mathrm{~mm} \mathrm{Hg}$ ) and median RV to systemic pressure ratio was 0.50 (IQR, 0.41-0.60). There were no operative deaths. Median hospital length of stay was 7 days (IQR, 6-8 days).

\section{Residual Pulmonary Stenosis and Valve Reinterventions}

Median RVOT peak gradient at hospital discharge was $25 \mathrm{~mm} \mathrm{Hg}$ (IQR, 18-30 mm Hg). Overall, 25 patients $(15.4 \%)$ underwent reintervention for residual valvar stenosis (all valve reinterventions occurred postdischarge). Fifteen patients underwent transcatheter balloon valvuloplasty alone, and 10 patients had a second operation with conversion to TAP after unsuccessful catheter-based therapy. Median time to reintervention was 123 days (IQR, 68-188 days). Seventeen of 25 PV reinterventions occurred within 6 months and the remainder occurred within 2 years of primary repair. By univariable Cox regression analysis, age at surgery, preoperative annulus $z$ score, and TPS were associated with risk for reintervention for residual stenosis (Table E1). Multivariable regression analysis demonstrated preoperative annulus $z$ score less than or equal to $-2.45(P=.036)$, younger age at surgery $(P=.001)$, and class II or III pulmonary stenosis-based TPS class $(P=.002)$ were independently associated with higher 

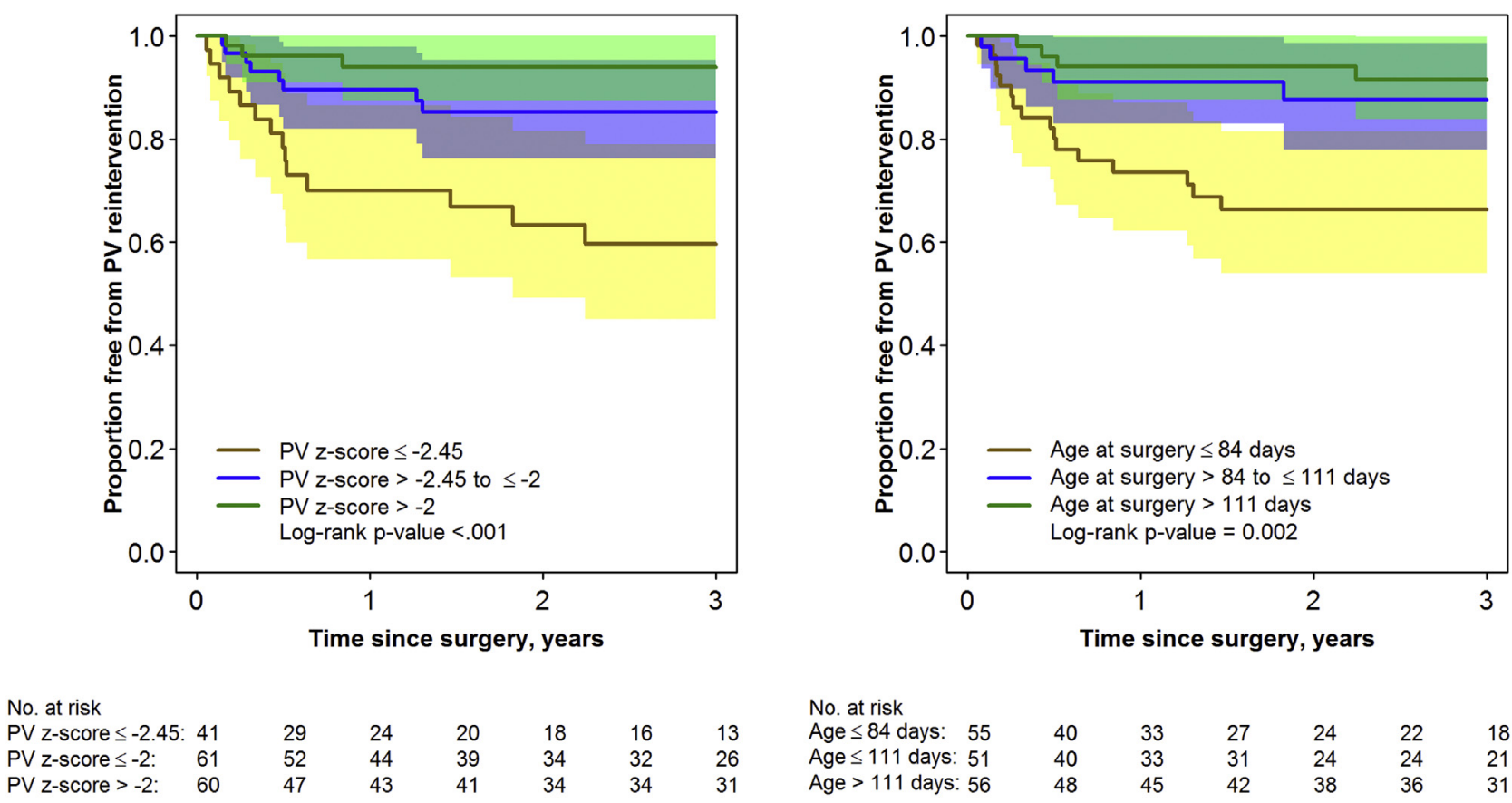

No. at risk

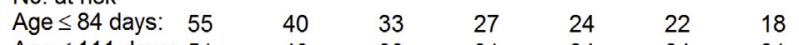

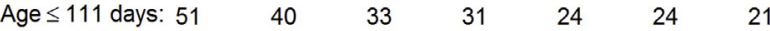

$\begin{array}{llllllll}\text { PV z-score > -2: } & 60 & 47 & 43 & 41 & 34 & 34 & 31\end{array}$

Age $>111 d$

48

$45 \quad 42$

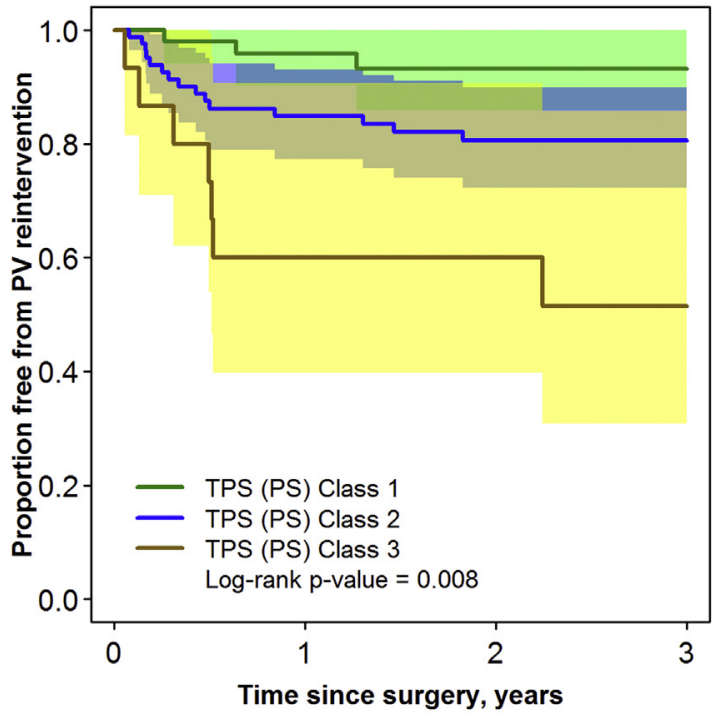

No. at risk

$\begin{array}{llllllll}\text { TPS (PS) Class 1: } & 56 & 48 & 39 & 31 & 28 & 27 & 21 \\ \text { TPS (PS) Class 2: } 90 & 68 & 63 & 60 & 51 & 49 & 43\end{array}$

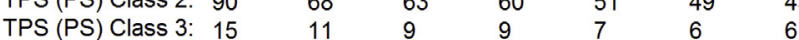

FIGURE 1. Freedom from pulmonary valve $(P V)$ reintervention for residual stenosis after valve-sparing repair, by preoperative annulus $z$ score, age at surgery, and technical performance score. TPS, Technical performance score; $P S$, pulmonary stenosis.

hazard of reintervention for residual PS (Table 2). Fifty-six percent of patients with a preoperative $\mathrm{PV}$ annulus $z$ score less than or equal to -2.45 required early reintervention for recurrent PS. Kaplan-Meier freedom from reintervention for residual PS is shown in Figure 1. Freedom from reintervention at 6 months postrepair was $83 \%$ among patients with unicuspid valve morphology, compared with
$87 \%$ and $96 \%$ among patients with bicuspid and tricuspid valve morphology, respectively $(P=.37)$.

\section{PV Competency}

The study cohort exhibited progressive PR after valvesparing repair with IBD. Freedom from at least moderate PR was $77 \%, 61 \%$, and $43 \%$ at 1,3 , and 5 years postrepair 


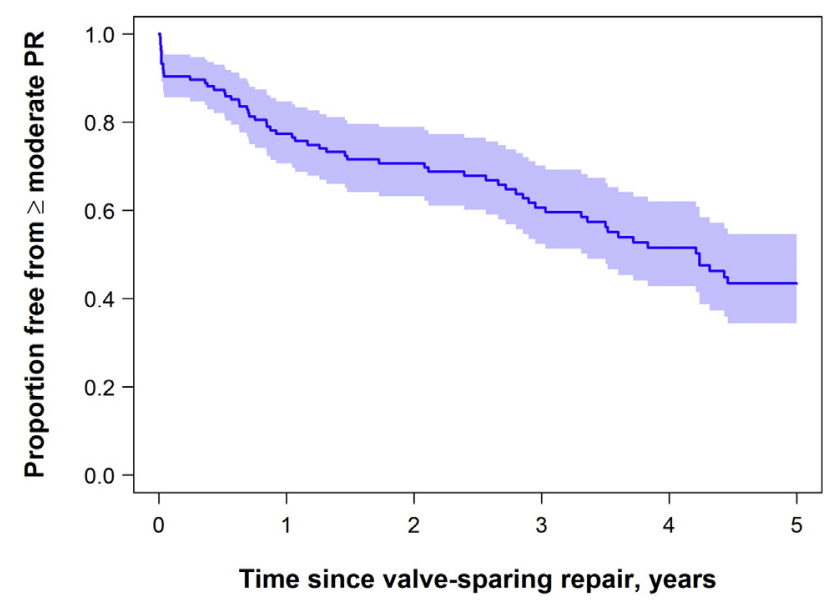

$\begin{array}{lllllll}\text { No. at risk } & 162 & 94 & 76 & 58 & 41 & 22\end{array}$

FIGURE 2. Estimated freedom from moderate or greater pulmonary regurgitation $(P R)$ after valve-sparing repair with intraoperative balloon dilation. Data were truncated at 8 years, with 1 additional event at 8.2 years.

(Figure 2). Univariable analysis demonstrated smaller preoperative PV annulus size, younger age at surgery, and abnormal leaflet appearance (eg, thickened/dysplastic), were associated with development of moderate or greater PR (Table E2). Multivariable Cox regression analysis showed preoperative PV annulus $z$ score less than or equal to -2.45 (hazard ratio, $2.31 ; P=.019$ ) and abnormal leaflet appearance (hazard ratio, $1.67 ; P=.040$ ) were independent predictors for earlier onset of at least moderate PR (Table E3). Age at surgery was not a predictor $(P=.194)$ after accounting for these 2 factors. Freedom from at least moderate PR stratified according to preoperative PV annulus $z$ score and valve leaflet appearance is detailed in Figure E1. Two patients (1\%) underwent late PV replacement at 7 and 8 years after primary repair for severe RV dilation and dysfunction secondary to severe PR.

\section{RV Dimensions: Valve-Sparing Versus TAP Repair}

Between January 1997 and December 2006, 177 ToF-PS patients underwent TAP repair at our institution. Fifty-three patients with serial echocardiogram studies were matched (1:1 matching by age and preoperative PV annulus size) to 53 valve-sparing patients. Mean preoperative PV $z$ score was $-2.26 \pm 0.55$ in the TAP group and $-2.21 \pm 0.65$ in the valve-sparing group. All TAP patients had documented severe PR on the first postdischarge echocardiogram. Table 3 outlines patient demographic characteristics, anatomic characteristics, and postoperative follow-up data for the matched cohorts. The incidence of early PV reintervention for residual stenosis was 13 in the valve-sparing cohort, compared with 1 the TAP group ( $P=.004)$ (Table E4). In the initial 1.5 years postrepair, the TAP cohort exhibited a significantly greater rate of $\mathrm{RV}$ dilation compared with valve-sparing patients $(P=.046)$. Beyond 1.5 years, RV dilation slowed in the TAP cohort, whereas the valvesparing cohort exhibited a higher rate of RV dilation $(P=.004)$, resulting in a similar mean RV EDA in TAP and valve-sparing patients as follow-up duration increased (Figure 3).

\section{Annulus Growth}

Mean PV annulus size increased from $6.6 \pm 1.3 \mathrm{~mm}(z$ score, -2.10$)$ preoperatively to $7.0 \pm 1.2 \mathrm{~mm}$ at discharge ( $z$ score, -1.99 ). Annular growth was observed throughout follow-up, with mean PV annulus $z$ score equal to $-0.98 \pm 0.88$ at 5 years postsurgery $(P<.001)$ (Figure 4$)$.

\section{DISCUSSION}

In this study, we evaluated all patients who underwent complete primary repair of ToF-PS with valve-sparing IBD technique at age 1 year or younger. Patients with significant annular hypoplasia and those younger than 3 months of age at the time of primary repair demonstrated higher rates of early reintervention for residual PS. Moreover, patients with significant residual RVOT gradient at discharge were at higher risk of early PV reintervention. The most important finding is that patients with ToF-PS who underwent valve-sparing repair with IBD developed progressive PV insufficiency. Furthermore, our analysis suggests that the degree of RV dilation at midterm follow-up was not significantly different among patients who underwent valve-sparing repair with IBD, compared with those repaired via transannular approach.

Based on previous experience with transcatheter balloon pulmonary valvotomy, ${ }^{20,21,26}$ our center adopted valve-sparing repair with IBD for patients with ToF-PS in 2007. 6,8 Our early experience with this strategy ( $\mathrm{n}=23$ ) demonstrated a $\mathrm{PV}$ reintervention rate of $26 \%{ }^{8}$ With increasing experience, we made several modifications to the surgical technique, including more extensive commissurotomy and extension of the infundibulotomy incision in a $T$-shaped fashion. Our balloon dilation strategy became less aggressive (ie, maximal balloon size to annulus ratio is 1.32 compared with 1.47 in the initial case series) due to concern that excessive dilation would result in early onset PR. ${ }^{8}$ Nonetheless, in the present study, $15 \%$ of patients required reintervention for residual PS within 2 years of primary repair. This suggests that our strategy of limited annular enlargement may have contributed to residual RVOT obstruction in certain high-risk groups, in particular patients with significant annular hypoplasia ( $z$ score less than -2.45). Finally, although not reaching statistical significance, this study suggests PV morphology is an important risk factor for both early valve reintervention and poor long-term leaflet durability. 
TABLE 3. Patient characteristics and follow-up data of the 2 matched surgical cohorts

\begin{tabular}{|c|c|c|c|}
\hline Characteristic & $\begin{array}{c}\text { Valve-sparing } \\
\text { repair } \\
(\mathbf{n}=\mathbf{5 3}) \\
\end{array}$ & $\begin{array}{c}\text { Transannular repair } \\
\quad(\mathbf{n}=\mathbf{5 3})\end{array}$ & $P$ value \\
\hline \multicolumn{4}{|l|}{ Demographic and anatomic data } \\
\hline Male & $27(50.9)$ & $36(67.9)$ & .113 \\
\hline Age at surgery (d) & $96 \pm 55$ & $83 \pm 49$ & .181 \\
\hline PV annulus $z$ score & $-2.21 \pm 0.55$ & $-2.26 \pm 0.65$ & .670 \\
\hline Body surface area $\left(\mathrm{m}^{2}\right)$ & $0.28 \pm 0.06$ & $0.27 \pm 0.04$ & .639 \\
\hline Prematurity (<37 wk) & $10(18.9)$ & $4(16.7)$ & .149 \\
\hline Chromosomal defect/syndrome & $5(9.4)$ & $11(24.4)$ & .068 \\
\hline Preoperative PV intervention & $5(9.4)$ & $2(3.9)$ & .437 \\
\hline \multicolumn{4}{|l|}{ Postoperative parameters } \\
\hline Right bundle branch block & $34(64)$ & $35(66)$ & 1.000 \\
\hline Operative mortality & 0 & 0 & \\
\hline Hospital length of stay (d) & $7.2 \pm 4.4$ & $8.9 \pm 6.8$ & .123 \\
\hline \multicolumn{4}{|l|}{ Follow-up outcomes } \\
\hline Duration of follow-up (y) & $4.94 \pm 2.39$ & $7.98 \pm 2.76$ & $<.001$ \\
\hline Early PV reintervention for stenosis & $13(25)$ & $1(2)$ & \\
\hline Catheter-based balloon dilation & $12(23)$ & $1(2)$ & \\
\hline Surgical reintervention & $5(9)$ & 0 & \\
\hline \multicolumn{4}{|l|}{ QRS duration (ms) } \\
\hline 5 y postsurgery & $108 \pm 23$ & $113 \pm 23$ & \\
\hline \multicolumn{4}{|l|}{ Right ventricular pressure $(\mathrm{mm} \mathrm{Hg})$} \\
\hline 5 y postsurgery & $38 \pm 15$ & $31 \pm 12$ & \\
\hline Late PV replacement & $2(4)$ & $24(45)$ & \\
\hline Late mortality & 0 & 0 & \\
\hline
\end{tabular}

Overall, the data suggests younger patients (age $<3$ months) and those with an annulus $z$ score less than -2.45 should undergo an alternative management strategy. Potential options include TAP repair, valve reconstruction, such as the monocusp technique, ${ }^{27}$ or alternative valve-sparing repair strategies. ${ }^{18,28}$ However, because none of these potential alternatives has shown long-term efficacy in patients with ToF-PS, the optimal surgical strategy remains unclear at this time.

The fundamental motivation for pursuing valve-sparing repair in patients with ToF is to prevent adverse RV remodeling. Several groups have adopted the valve-sparing repair technique of intraoperative balloon valvuloplasty over the past decade. ${ }^{8,10,16,17,19}$ Early reports showed encouraging results, yet data examining the longevity of this repair strategy have been lacking. We observed that patients with ToF-PS who undergo valve-sparing repair with IBD developed progressive pulmonary insufficiency. These results are consistent with previous studies suggesting late development of PR following valve-sparing repair. ${ }^{8,19,28}$ Our initial case series of 23 patients demonstrated $50 \%$ of patients with greater than mild PR, and $15 \%$ with severe PR at 1.5 years after valve-sparing repair. ${ }^{8}$ Moreover, in a series of 30 patients with ToF-PS,
Vida and colleagues ${ }^{19}$ reported a $20 \%$ incidence of moderate $\mathrm{PR}$ at approximately 1 year after valve-sparing repair with IBD.

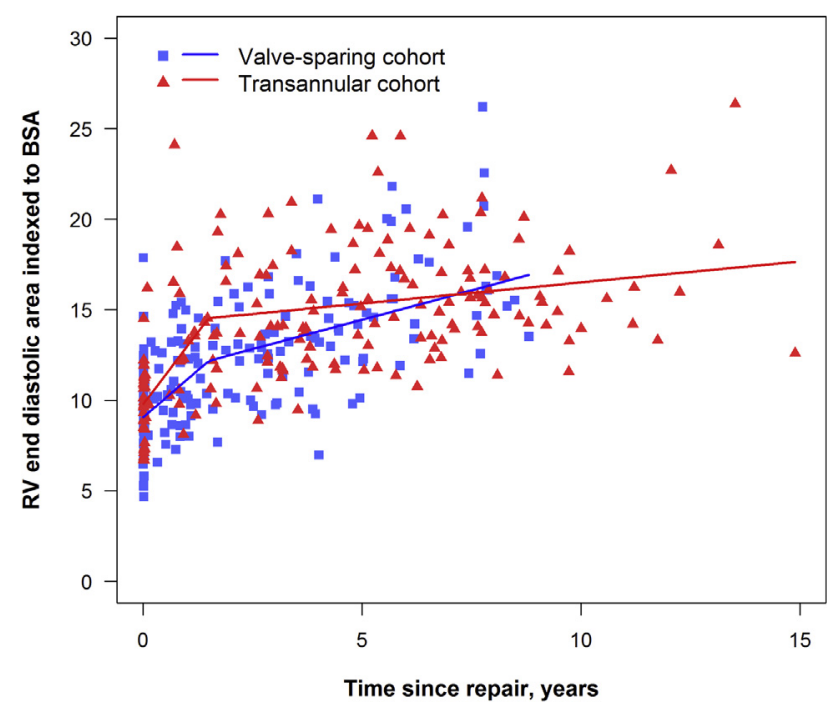

FIGURE 3. Indexed right ventricular $(R V)$ end diastolic area over time by surgical cohort. Blue squares indicate valve-sparing cohort $(\mathrm{n}=53)$. Red triangles indicate transannular cohort $(\mathrm{n}=53)$. BSA, Body surface area. 


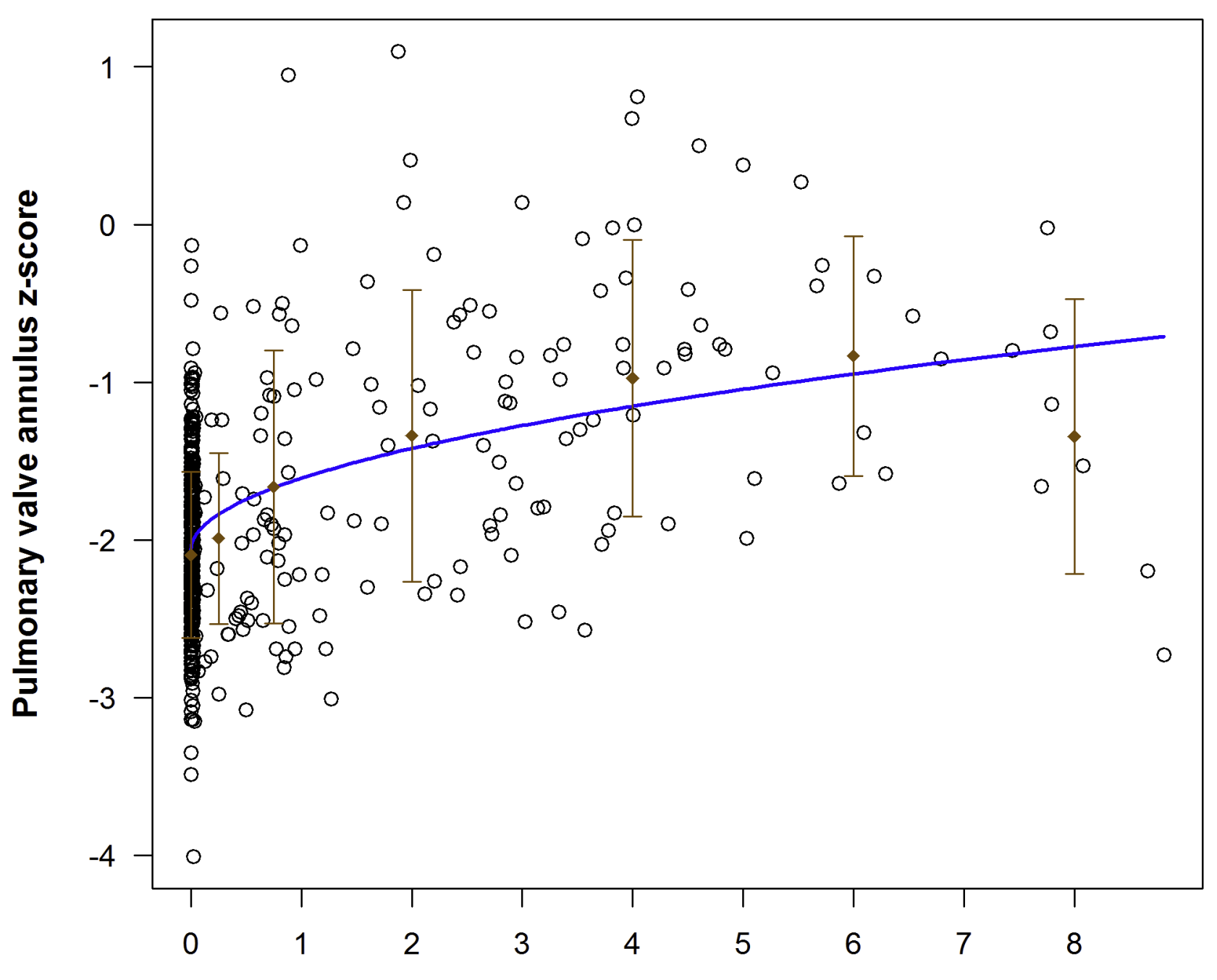

Time since valve-sparing repair, years

FIGURE 4. Pulmonary valve annulus size after valve-sparing tetralogy of Fallot repair. Blue line indicates predicted annulus $z$ score.

Our multivariable analysis found that significant annular hypoplasia ( $z$ score less than or equal to -2.45 ) and thickened/dysplastic valve leaflets were independent predictors for earlier onset of valvar incompetence, suggesting valve-sparing repair with IBD may not be the optimal approach in these patient subgroups. This may be particularly relevant for patients with an annular $z$ score less than -2.45 because they also face a higher risk of early reintervention for residual valve stenosis. Overall, it appears that the hemodynamic benefits of valve-sparing repair with IBD are relatively short-lived because most patients develop significant PR well within the first decade of life. Although the observed lack of valve leaflet remodeling certainly warrants further investigation, these data suggest that valve-sparing repair with IBD is not a suitable longterm solution to preserve PV function in patients with ToF-PS.
Due to the relatively young age of the study cohort, few patients had undergone evaluation with cardiac magnetic resonance imaging, thereby limiting our assessment of RV dimensions to 2-dimensional TTE studies. We acknowledge the inherent limitations of 2-dimensional echocardiogrambased volumetric analysis of RV dimensions. ${ }^{23,26}$ Nonetheless, 2-dimensional TTE remains the primary imaging modality for postoperative follow-up, particularly during the first decade of life. Furthermore, assessment of $\mathrm{RV}$ size was in accordance with published echocardiographic guidelines ${ }^{25,29}$ in both cohorts. Our analysis demonstrates that RV enlargement is delayed initially in patients undergoing valve-sparing procedure, then increases as PR worsens. Similar degrees of RV dilation in valve-sparing and TAP patients at 5 years suggests that longer-term RV remodeling is equivalent for patients with repaired ToF with progressive versus immediate onset 
pulmonary insufficiency. Although further prospective analyses are required, it appears that patients with ToF-PS treated via valve-sparing IBD technique may be on a similar trajectory as those who undergo TAP repair, in terms of requirement for late $\mathrm{PV}$ replacement.

This retrospective, single-center analysis has several limitations. Assessment of PR severity was based on semiquantitative echocardiogram-based assessment, and many patients did not have echocardiogram images available for independent review. Onset of PR and RV dilation are limited by the timing of echocardiographic follow-up. Furthermore, assessment of longitudinal RV remodeling was limited to measurement of end diastolic dimensions on 2-dimensional TTE.

\section{CONCLUSIONS}

Patients with ToF-PS who undergo valve-sparing repair with IBD develop progressive PR. Compared with traditional TAP repair, the timing and extent of RV dilation appears similar for patients who have undergone valve-sparing repair with IBD. In patients with significant annular hypoplasia, and those younger than 3 months of age at repair, alternative surgical approaches should be explored to minimize the risk of early valve reintervention for residual PS. Although ToF patients who undergo VSIBD repair exhibit significant longitudinal PV annular growth, the observed lack of valve leaflet remodeling warrants further investigation. The results of this study suggest that valve-sparing repair with IBD is not a suitable longterm solution to preserve PV function in patients with ToF.

\section{Webcast}

You can watch a Webcast of this AATS meeting presentation by going to: https://aats.blob.core.windows.net/media/ 17AM/2017-05-01/RM312/05-01-17_Room312_1418_ Hofferberth.mp4.

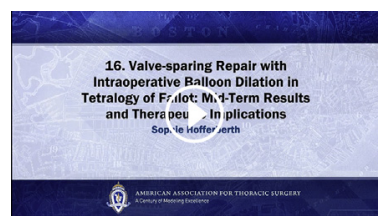

\section{Conflict of Interest Statement}

Authors have nothing to disclose with regard to commercial support.

\section{References}

1. van der Linde D, Konings EE, Slager MA, Witsenburg M, Helbing WA, Takkenberg JJ, et al. Birth prevalence of congenital heart disease worldwide: a systematic review and meta-analysis. J Am Coll Cardiol. 2011;58:2241-7.

2. Villafane J, Feinstein JA, Jenkins KJ, Vincent RN, Walsh EP, Dubin AM, et al. Hot topics in tetralogy of Fallot. J Am Coll Cardiol. 2013;62:2155-66.
3. Bacha EA, Scheule AM, Zurakowski D, Erickson LC, Hung J, Lang P, et al. Long-term results after early primary repair of tetralogy of Fallot. J Thorac Cardiovasc Surg. 2001;122:154-61.

4. Parry AJ, McElhinney DB, Kung GC, Reddy VM, Brook MM, Hanley FL. Elective primary repair of acyanotic tetralogy of Fallot in early infancy: overall outcome and impact on the pulmonary valve. J Am Coll Cardiol. 2000;36:2279-83.

5. Anagnostopoulos P, Azakie A, Natarajan S, Alphonso N, Brook MM, Karl TR. Pulmonary valve cusp augmentation with autologous pericardium may improve early outcome for tetralogy of Fallot. J Thorac Cardiovasc Surg. 2007;133:640-7.

6. Bacha EA, Marshall AC, McElhinney DB, del Nido PJ. Expanding the hybrid concept in congenital heart surgery. Semin Thorac Cardiovasc Surg Pediatr Card Surg Annu. 2007;146-50.

7. Mavroudis C, Mavroudis CD, Frost J. Native pulmonary valve restoration after remote tetralogy of Fallot repair: how to do it. World J Pediatr Congenit Heart Surg. 2013;4:422-6.

8. Robinson JD, Rathod RH, Brown DW, Del Nido PJ, Lock JE, McElhinney DB, et al. The evolving role of intraoperative balloon pulmonary valvuloplasty in valvesparing repair of tetralogy of Fallot. J Thorac Cardiovasc Surg. 2011;142:1367-73.

9. Sung SC, Kim S, Woo JS, Lee YS. Pulmonic valve annular enlargement with valve repair in tetralogy of Fallot. Ann Thorac Surg. 2003;75:303-5.

10. Vida VL, Padalino MA, Maschietto N, Biffanti R, Anderson RH, Milanesi O, et al. The balloon dilation of the pulmonary valve during early repair of tetralogy of Fallot. Catheter Cardiovasc Interv. 2012;80:915-21.

11. Al Habib HF, Jacobs JP, Mavroudis C, Tchervenkov CI, O'Brien SM Mohammadi S, et al. Contemporary patterns of management of tetralogy of Fallot: data from the Society of Thoracic Surgeons Database. Ann Thorac Surg. 2010;90:813-9; discussion 19-20.

12. Geva T. Indications and timing of pulmonary valve replacement after tetralogy of Fallot repair. Semin Thorac Cardiovasc Surg Pediatr Card Surg Annu. 2006;11-22.

13. Geva T, Sandweiss BM, Gauvreau K, Lock JE, Powell AJ. Factors associated with impaired clinical status in long-term survivors of tetralogy of Fallot repair evaluated by magnetic resonance imaging. J Am Coll Cardiol. 2004;43:1068-74.

14. Murphy JG, Gersh BJ, Mair DD, Fuster V, McGoon MD, Ilstrup DM, et al. Longterm outcome in patients undergoing surgical repair of tetralogy of Fallot. $N$ Engl J Med. 1993;329:593-9.

15. Hickey EJ, Veldtman G, Bradley TJ, Gengsakul A, Manlhiot C, Williams WG et al. Late risk of outcomes for adults with repaired tetralogy of Fallot from an inception cohort spanning four decades. Eur J Cardiothorac Surg. 2009;35: 156-64; discussion 64.

16. Bautista-Hernandez V, Cardenas I, Martinez-Bendayan I, Loyola H, Rueda F, Portela F. Valve-sparing tetralogy of Fallot repair with intraoperative dilation of the pulmonary valve. Pediatr Cardiol. 2013;34:918-23.

17. Sen DG, Najjar M, Yimaz B, Levasseur SM, Kalessan B, Quaegebeur JM, et al. Aiming to preserve pulmonary valve function in tetralogy of fallot repair: comparing a new approach to traditional management. Pediatr Cardiol. 2016;37:818-25.

18. Vida VL, Angelini A, Guariento A, Frescura C, Fedrigo M, Padalino M, et al. Preserving the pulmonary valve during early repair of tetralogy of Fallot: anatomic substrates and surgical strategies. J Thorac Cardiovasc Surg. 2015;149:1358-63.e1.

19. Vida VL, Guariento A, Castaldi B, Sambugaro M, Padalino MA, Milanesi O, et al. Evolving strategies for preserving the pulmonary valve during early repair of tetralogy of Fallot: mid-term results. J Thorac Cardiovasc Surg. 2014;147: 687-94; discussion 94-6.

20. Radtke W, Keane JF, Fellows KE, Lang P, Lock JE. Percutaneous balloon valvotomy of congenital pulmonary stenosis using oversized balloons. J Am Coll Cardiol. 1986;8:909-15.

21. Ring JC, Kulik TJ, Burke BA, Lock JE. Morphologic changes induced by dilation of the pulmonary valve anulus with overlarge balloons in normal newborn lambs Am J Cardiol. 1985;55:210-4.

22. Nathan M, Marshall AC, Kerstein J, Liu H, Fynn-Thompson F, Baird CW, et al. Technical performance score as predictor for post-discharge reintervention in valve-sparing tetralogy of Fallot repair. Semin Thorac Cardiovasc Surg. 2014; 26:297-303.

23. Helbing WA, Bosch HG, Maliepaard C, Rebergen SA, van der Geest RJ, Hansen B, et al. Comparison of echocardiographic methods with magnetic resonance imaging for assessment of right ventricular function in children. Am J Cardiol. 1995;76:589-94.

24. Lang RM, Bierig M, Devereux RB, Flachskampf FA, Foster E, Pellikka PA, et al. Recommendations for chamber quantification: a report from the American Society of Echocardiography's Guidelines and Standards Committee and the Chamber Quantification Writing Group, developed in conjunction with the European Association of Echocardiography, 
a branch of the European Society of Cardiology. J Am Soc Echocardiogr. 2005; 18:1440-63.

25. Lopez L, Colan SD, Frommelt PC, Ensing GJ, Kendall K, Younoszai AK, et al. Recommendations for quantification methods during the performance of a pediatric echocardiogram: a report from the Pediatric Measurements Writing Group of the American Society of Echocardiography Pediatric and Congenital Heart Disease Council. J Am Soc Echocardiogr. 2010;23:465-95. quiz 576-7.

26. Sluysmans T, Neven B, Rubay J, Lintermans J, Ovaert C, Mucumbitsi J, et al Early balloon dilatation of the pulmonary valve in infants with tetralogy of Fallot. Risks and benefits. Circulation. 1995;91:1506-11.

27. Kumar M, Turrentine MW, Rodefeld MD, Bell T, Brown JW. Right ventricular outflow tract reconstruction with a polytetrafluoroethylene monocusp valve: a 20-year experience. Semin Thorac Cardiovasc Surg. 2016;28:463-70.

28. Bacha E. Valve-sparing or valve reconstruction options in tetralogy of Fallot surgery. Semin Thorac Cardiovasc Surg Pediatr Card Surg Annu. 2017;20:79-83.

29. Rudski LG, Lai WW, Afilalo J, Hua L, Handschumacher MD, Chandrasekaran K, et al. Guidelines for the echocardiographic assessment of the right heart in adults: a report from the American Society of Echocardiography endorsed by the European Association of Echocardiography, a registered branch of the European Society of Cardiology, and the Canadian Society of Echocardiography. J Am Soc Echocardiogr. 2010;23:685-713. quiz 86-8.

Key Words: Tetralogy of Fallot, valve-sparing repair, pulmonary regurgitation, right ventricular dilation

\section{Discussion}

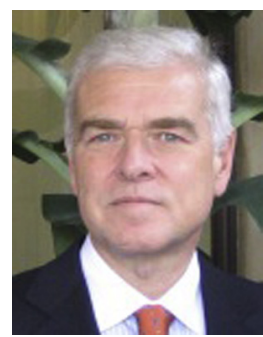

Dr Giovanni Stellin (Padova, Italy). I would like to congratulate Dr Hofferberth for the very nice presentation, and also for providing me the manuscript in advance. There are a few things that are not clear to me and perhaps to the rest of the audience as well.

First: Which are your indications for balloon dilatations? Your mean pulmonary valve (PV) $z$ score was 2.2. Do you dilate PV also in so-called pink tetralogy of Fallot where the $z$ score is close to zero?

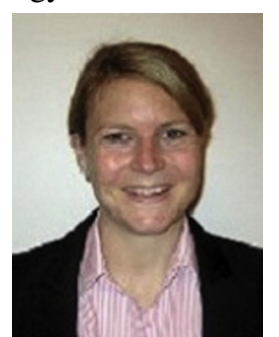

Dr Hofferberth. Thank you very much, Dr Stellin. I really appreciate your questions and comments. The median annulus $z$ score was -2.2 for this patient cohort. During the study period, the valve-sparing/balloon dilation repair strategy was performed in the vast majority of patients with ToF-PS undergoing tetralogy of Fallot-pulmonary stenosis and who presented to our institution. In the preceding era, these patients had undergone transannular patch repair. There was a small number of patients who had an annulus $z$ score of between -1 and 0 who did undergo the valve-sparing repair with intraoperative balloon dilation; however, there were also patients with a $z$ score in this range who underwent commissurotomy without adjunctive balloon dilation.

Dr Stellin. In other words, you have been selecting your patients, because 35 patients had a $z$ score $<2.5$. What is the lowest PV $z$ score that has been treated with balloon dilatation? Have you performed any reconstruction of the PV after dilatation? Where there any balloon dilatations that failed and were turned into transannular patch repair?

Dr Hofferberth. Thank you for your questions. The smallest $z$ score in this cohort was -3.5. As you mentioned, there were 35 patients who had a $z$ score that was less than -2.5 . There were 32 patients who had a leaflet tear detected at the time of the primary repair. Eighteen patients underwent a procedure to repair the leaflet tear, 11 patients had single suture repair, and 6 patients underwent patch augmentation with autologous pericardium. One of these patients did have a conversion to a transannular patch.

Dr Stellin. You didn't perform balloon dilatation for all patients. Your lowest $z$ score was -3.5 or -4 . How about all the other patients with a $z$ score less than -3.5 ? Have you excluded them from your experience?

Dr Hofferberth. Among all patients who underwent surgical repair at our center from 2007 to 2015, 162 underwent valve-sparing with intraoperative balloon dilation. Fortyfive patients underwent valve-sparing repair via commissurotomy only. This patient subgroup had a median annulus $z$ score of -1.8 . there was also a subset of 40 patients with tetralogy of Fallot-pulmonary stenosis with severe annular hypoplasia who had a transannular patch reconstruction.

Dr Stellin. In other words, there were some patients who underwent a transannular patch procedure. Only the middle-size $z$ score patients underwent pulmonary balloon dilatation?

Dr Hofferberth. Yes, that is correct.

Dr Stellin. In your experience there is an early reintervention for right ventricular outflow tract revision of $15 \%$, which is quite high, and I wonder at what level was the obstruction.

Dr Hofferberth. To address the technical question regarding our ventriculotomy approach, it was an infundibular incision that was extended up to the annulus in a $T$-shaped fashion. Overall, 30 patients required reintervention for residual right ventricular outflow tract stenosis. One patient required reintervention at the subvalvular level, 4 patients underwent branch pulmonary artery reintervention, and 25 patients underwent reintervention for residual obstruction at the level of the PV. The multivariable regression analysis is based only on reinterventions at the level of the PV.

Among the important take home points of this study is that patients with an annulus $z$ score $<-2.45$ and those younger than age 3 months at the time of surgery, experienced higher rates of early reintervention for residual stenosis.

Dr Stellin. Another technical question. You have been using low pressure balloons and you oversize balloons in according to the calculated PV annulus size. There are notes in the literature where you shouldn't oversize balloons to avoid a tear of the valve leaflets, which are difficult to repair. Would you agree that this partial success of your balloon dilatation might be related to oversized balloons? 
Dr Hofferberth. Thank you, Dr Stellin. That is a very important point. The balloon dilation technique was developed in conjunction with the interventional cardiology team at our institution who had performed this strategy in patients with isolated pulmonary valve stenosis. Their experience demonstrated that dilating the annulus beyond a balloon to annulus ratio of 1.5 was associated with higher rates of annulus tear. In the initial valve-sparing tetralogy of Fallot repair that was reported from Boston, the balloon to annulus ratio was 1.47 , whereas in the present study the median balloon ratio was 1.32. This highlights that our balloon dilation strategy became less aggressive in the latter part of the study period.

When you look at the numbers, what this really equates to for individual patients is that our balloon dilation technique acutely increased the annulus size by 1-unit $z$ score only. This indicates the extent of balloon dilation is actually quite limited with our approach, especially when compared with other groups.

Dr Stellin. It is obvious that there is a difference between balloon dilating a valve with a closed chest in a catheterization lab and ballooning the PV during surgery.

My last question: You are concluding that balloon valve dilatations during tetralogy of Fallot repair haven't really shown an improved result over the classic transannular patch procedure. In our experience, we have different results. It is still a technique in evolution. We have different results. After a mean follow-up of 5 years, only $20 \%$ of patients, the worst ones, showed a PV moderate regurgitation. Twenty percent showed a competent valve or a mild regurgitation.

Do you think that we should learn a little bit more from these techniques of valve preserving and also avoiding a large ventriculotomy to obtain better results in the long-term?

Dr Hofferberth. Thank you very much, Dr Stellin. My hope is that today we will have further opportunity to discuss each of these points. Questions still remain regarding the indications for performing valve-sparing repair and what techniques have the best short- and longterm outcomes. I think it is important to highlight that there are significant differences in the technical approaches employed by the various centers currently performing valvesparing tetralogy of Fallot repair. For example, I believe that $60 \%$ of the patients in your series underwent additional valve plasty procedures. Our valve-sparing strategy has consisted of commissurotomy followed by annulus balloon dilation; however, there were no additional valve plasty maneuvers performed in the present study cohort. I also noted that your center's study from 2014 reported a 20\% incidence of pulmonary regurgitation at 400-day follow-up. I think for the wider surgical community it will be important to evaluate and compare each of the different valve-sparing techniques to determine the most optimal path forward in the management of this patient population.
Dr Stellin. Again I would like to congratulate you for your nice and clear presentation and to thank you for the beautiful, high-class manuscript that you sent to me.

Dr Hani Najm (Cleveland, Ohio). Very important data. I really enjoyed it. This brings out, especially with the last curve, that really the essence of the behavior of tetralogy that we want to preserve is right ventricular function, and you have a fairly generous right ventriculotomy just to preserve the pulmonary annulus. What is going to happen is that curve, that blue curve, is going to continue to go even beyond the original transannular patch, which means that an infundibular incision with a valve preservation, a large infundibular incision with a patch is as bad as doing a limited or even less of a transannular incision. The bad ones, anyway, when you preserve them, they are going to come back early, you have shown that, and the other ones that have been successful, they come back with regurgitation anyway. It is bad right ventricular function, and the incision in the infundibulum, that has to be. Is it the actual pulmonary annulus or is it the ventricular anatomy and function and morphology that we have preserved for the long-term?

Dr Hofferberth. Thank you very much for your comments. I think it is important to highlight that our evaluation of the right ventricle was limited to a volumetric analysis obtained from serial 2-dimensional echocardiogram measurements of end-diastolic area. We understand the limitations of this analysis and certainly it does need to be validated by follow-up studies using other imaging modalities, such as cardiac magnetic resonance imaging. The issue was that most patients in the valve-sparing cohort had only undergone 2-dimensional echocardiogram imaging during follow-up due to their young age. So I think before we can make conclusive statements regarding the rate and extent of right ventricular dilation after valvesparing repair, further imaging analysis is required.

Longitudinal changes in right ventricular function post valve-sparing repair also warrant further investigation, because it is not only the size of the right ventricle that matters.

Assessment of right ventricular strain, changes in ejection fraction and interplay with the left ventricle are all areas of active investigation.

Overall, I think further studies are required before we can conclude whether one approach is inferior to the other, but certainly these data highlight that further prospective investigation is necessary.

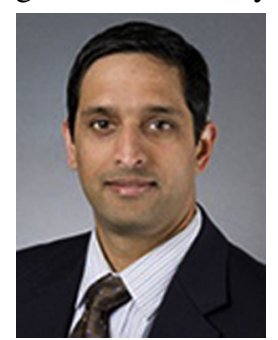

Dr Sitaram Emani (Boston, Mass). I would add that regurgitation progressed as the PV started to leak, suggesting that pulmonary regurgitation as the mechanism of right ventricle dilation. I caution about condemning an infundibulotomy as the culprit for changes in right ventricular function. 


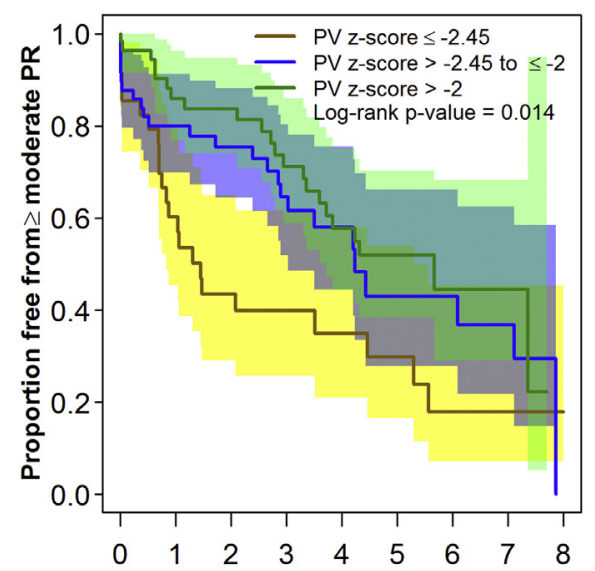

Time since surgery, years

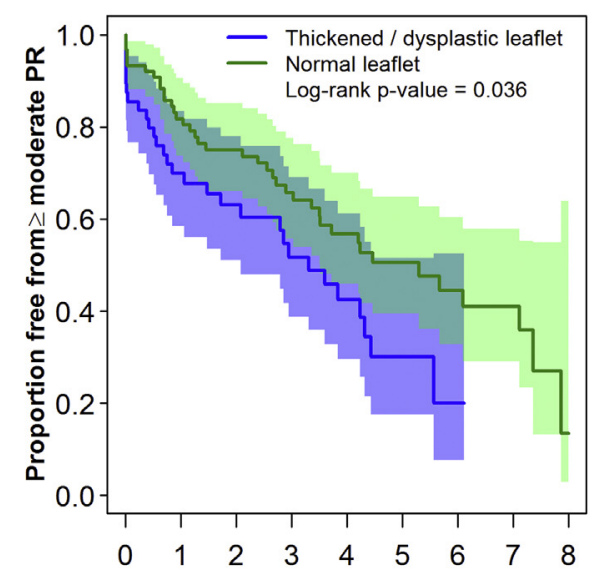

Time since surgery, years

$\begin{array}{llllll}\text { No. at risk } & & & & & \\ \text { PV z-score } \leq-2.45: & 41 & 12 & 7 & 1 & 1 \\ \text { PV z-score } \leq-2: & 61 & 30 & 13 & 7 & 0 \\ \text { PV z-score >-2: } & 60 & 34 & 21 & 6 & 0\end{array}$

No. at risk

$\begin{array}{llllll}\text { Abnormal leaflet: } & 64 & 23 & 12 & 1 & 0 \\ \text { Normal leaflet: } & 97 & 52 & 29 & 13 & 1\end{array}$

FIGURE E1. Estimated freedom from moderate or greater pulmonary regurgitation $(P R)$ by preoperative pulmonary valve $z$ score tertile and leaflet appearance (thickened/dysplastic vs normal). $P V$, Pulmonary valve. 
TABLE E1. Univariate Cox regression analysis of factors associated with pulmonary valve (PV) reintervention $(\mathrm{N}=162$; number of reinterventions $=\mathbf{2 5}$ )

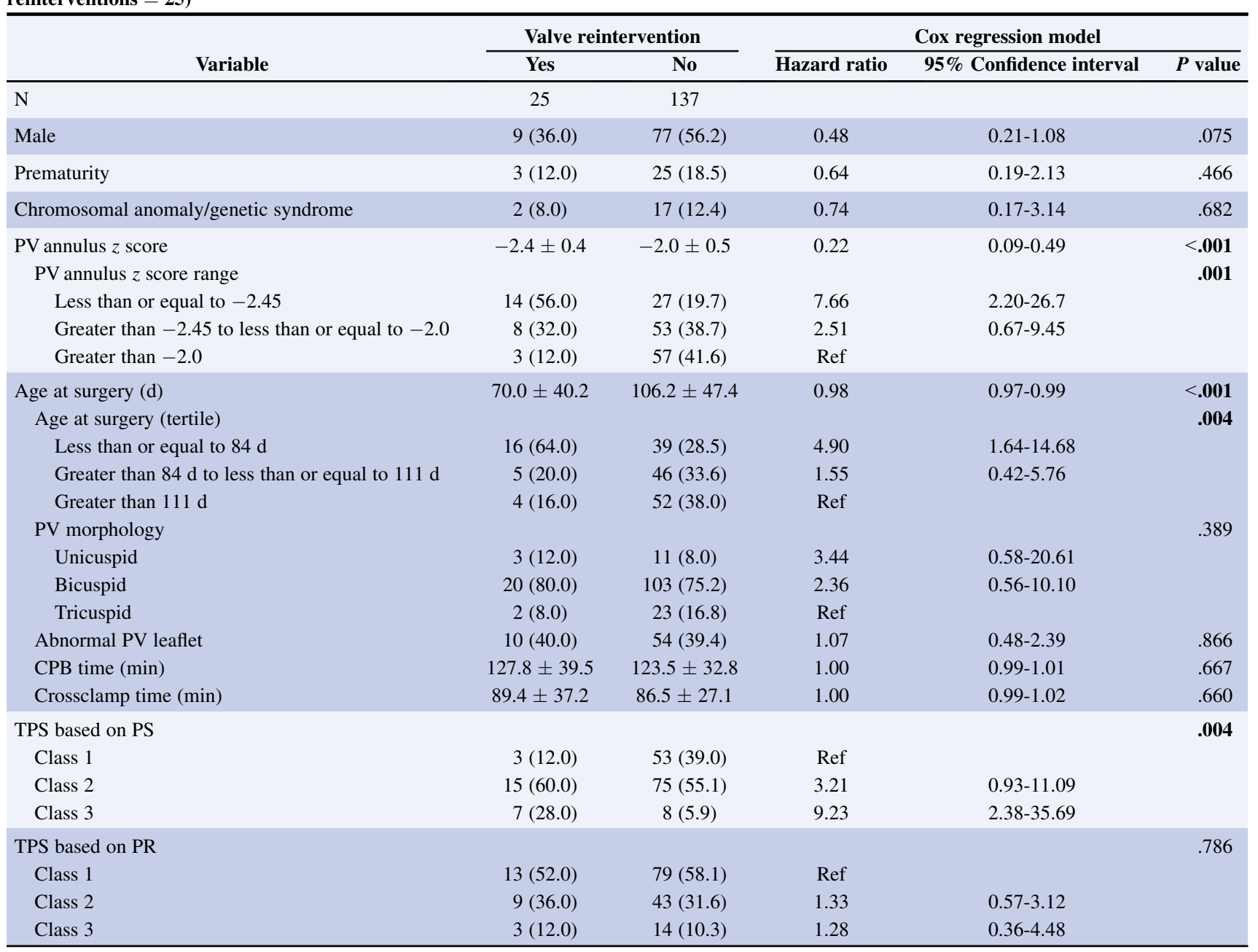

Values are presented as $\mathrm{n}(\%)$ or mean \pm standard deviation. Bold in the table presents patient-based and operative characteristics and the association with early pulmonary valve reintervention for residual stenosis. Univariate Cox regression modeling demonstrated factors associated with a higher hazard of reintervention are (1) smaller preoperative PV annulus $z$ score (56\% of patients with an annulus $z$ score $<-2.45$ required early valve reintervention); (2) younger age at surgery (64\% of patients who underwent early PV reintervention underwent primary repair at $\leq 84$ days of age; and (3) residual peak RVOT gradient of $>40$ mm Hg (class III TPS). PV, Pulmonary valve; Ref, reference category; $C P B$, cardiopulmonary bypass; $T P S$, technical performance score; $P S$, pulmonary stenosis; $P R$, pulmonary regurgitation. 
TABLE E2. Univariate Cox regression analysis of patient-based factors associated with development of moderate or greater pulmonary regurgitation $(\mathbf{P R})(\mathrm{N}=162)$

\begin{tabular}{|c|c|c|c|c|c|}
\hline \multirow[b]{2}{*}{ Variable } & \multicolumn{2}{|c|}{ Moderate or greater PR } & \multicolumn{3}{|c|}{ Cox regression model } \\
\hline & Yes & No & Hazard ratio & 95\% Confidence interval & $P$ value \\
\hline $\mathrm{N}$ & 71 & 91 & & & \\
\hline Male & $42(59.2)$ & $44(48.4)$ & 1.25 & $0.77-2.02$ & .371 \\
\hline Prematurity & $15(21.1)$ & $13(14.6)$ & 1.09 & $0.61-1.97$ & .772 \\
\hline Chromosomal anomaly/genetic syndrome & $8(11.3)$ & $11(12.2)$ & 1.38 & $0.66-2.89$ & .398 \\
\hline PV annulus $z$ score & $-2.2 \pm 0.5$ & $-2.0 \pm 0.5$ & 0.56 & $0.35-0.89$ & .014 \\
\hline PV annulus $z$ score & & & & & .017 \\
\hline Less than or equal to -2.45 & $24(33.8)$ & $17(18.7)$ & 2.32 & $1.28-4.19$ & \\
\hline Greater than -2.45 to less than or equal to $-2.0^{*}$ & $25(35.2)$ & $36(39.6)$ & 1.31 & $0.73-2.33$ & \\
\hline Greater than -2.0 & $22(31.0)$ & $38(41.8)$ & Ref & & \\
\hline Age at surgery $(d)$ & $95.5 \pm 54.5$ & $104.5 \pm 42.3$ & 0.99 & $0.989-1.00$ & .061 \\
\hline Age at surgery tertile & & & & & .022 \\
\hline Less than or equal to $84 \mathrm{~d}$ & $31(43.7)$ & $24(26.4)$ & 1.92 & $1.11-3.34$ & \\
\hline Greater than 84 to less than or equal to $111 \mathrm{~d}$ & $17(23.9)$ & $34(37.4)$ & 0.96 & $0.51-1.81$ & \\
\hline Greater than $111 \mathrm{~d}$ & $23(32.4)$ & $33(36.3)$ & Ref & & \\
\hline PV morphology $\dagger$ & & & & & .340 \\
\hline Unicuspid & $8(11.3)$ & $6(6.6)$ & 1.99 & $0.78-5.07$ & \\
\hline Bicuspid & $53(74.6)$ & $70(76.9)$ & 1.24 & $0.63-2.44$ & \\
\hline Tricuspid & $10(14.1)$ & $15(16.5)$ & Ref & & \\
\hline Abnormal PV leaflet & $30(42.3)$ & $34(37.8)$ & 1.68 & $1.03-2.73$ & .038 \\
\hline
\end{tabular}

Values are presented as $\mathrm{n}(\%)$ or mean \pm standard deviation. Bold in the table presents a univariate Cox regression analysis of patient-based factors associated with development of at least moderate pulmonary regurgitation. Patient-based factors associated with a higher hazard of developing at least moderate PR are (1) smaller preoperative PV annulus z score, (2) age at surgery ( $\leq 84$ days), and (3) thickened or dysplastic valve leaflet. $P R$, Pulmonary regurgitation; $P V$, pulmonary valve; Ref, reference category. *Hazard ratio, 1.77 ; 95\% confidence interval, $1.00-3.14 ; P=.049$. $\dagger$ Hazard ratio, $1.60 ; 95 \%$ confidence interval, $0.75-3.40 ; P=.22$.

TABLE E3. Multivariable Cox regression model of factors associated with development of moderate or greater pulmonary regurgitation $\left(\mathrm{N}=162\right.$; pseudo $\left.R^{2}=0.07\right)$

\begin{tabular}{lccc}
\hline \multicolumn{1}{c}{ Variable } & Hazard & $\mathbf{9 5} \%$ Confidence & \\
ratio & interval & $\boldsymbol{P}$ value \\
\hline Pulmonary valve annulus $z$ score & & & $\mathbf{. 0 1 9}$ \\
$\quad$ Less than or equal to $-2.45^{*}$ & 2.31 & $1.28-4.18$ & \\
Greater than -2.45 to less than & 1.37 & $0.77-2.44$ & \\
$\quad$ or equal to -2.0 & & & \\
Greater than -2.0 & Ref & & $\mathbf{. 0 4 0}$ \\
Thickened/dysplastic valve & & & \\
$\quad$ leaflets & & & \\
$\quad$ Yes & 1.67 & $1.02-2.71$ & \\
No & Ref & & \\
\hline
\end{tabular}

$\overline{\text { Bold indicates multivariable regression analysis that shows the factors independently }}$ associated with a higher hazard of at least moderate PR are (1) preoperative PV annulus $z$ score $\leq-2.45$ and (2) abnormal leaflet appearance (thickened or dysplastic). Ref, Reference category. *Hazard ratio, 1.69; $95 \%$ confidence interval, 0.95-2.99. 
TABLE E4. Five-year incidence of reintervention for 2 matched surgical cohorts

\begin{tabular}{lccc}
\hline \multicolumn{1}{c}{ Variable } & $\begin{array}{c}\text { Valve-sparing cohort } \\
(\mathbf{n}=\mathbf{5 3})\end{array}$ & $\begin{array}{c}\text { Transannular cohort } \\
(\mathbf{n}=\mathbf{5 3})\end{array}$ & Poisson $\boldsymbol{P}$ value \\
\hline Total follow-up years & 169.70 & 253.71 \\
\hline PV reintervention* & $13(7.66)$ & $1(0.39)$ \\
\hline Total follow-up years & 190.65 & 246.19 \\
\hline Surgical reintervention* & $8(4.20)$ & $4(1.62)$ \\
\hline Total follow-up years & 162.73 & 236.28 \\
Catheter reintervention* & $15(9.22)$ & $6(2.54)$ \\
\hline PV balloon dilation & $12(7.37)$ & $3(1.27)$ \\
\hline Branch PA dilation/stenting & $4(2.46)$ & $3(1.27)$ \\
\hline Values are presented as n or $n(\%) . P V$, Pulmonary valve; $P A$, pulmonary artery. *Incidence rate is defined by number of patients with a reintervention divided by total follow-up \\
years $\times 100$.
\end{tabular}

